Some have argued that industrial funding has undue influence on the research agenda. ${ }^{10}$ Others state that a submitted manuscript should be considered the intellectual property of authors, not the study sponsor. ${ }^{11}$ A reliable assessment of this question depends on the transparency of the reporting. ${ }^{1}$ The CONSORT statement ${ }^{812}$ and similar standardised reporting guidelines could consider the importance of adequate reporting of funding. The reader can make an assessment only if the information is clearly presented.

We thank Christian Gluud for critical revision of an earlier draft of the paper.

Contributors: See bmj.com

Funding: Danish Medical Research Council; 1991 Pharmacy Foundation, Denmark; Copenhagen Hospital Corporation Medical Research Council; Danish Institute of Health Technology Assessments.

Competing interests: None declared.

1 Smith R. Beyond conflict of interest. Transparency is the key. $B M$ J $1998 ; 317: 291-2$
2 Djulbegovic B, Lacevic M, Cantor A, Fields KK, Bennett CL, Adams JR, et al. The uncertainty principle and industry-sponsored research. Lancet 2000;356:635-8.

3 Wahlbeck K, Adams C. Beyond conflict of interest. Sponsored drug trials show more-favourable outcomes. BMJ 1999;318:465.

4 Schulz KF, Chalmers I, Hayes RJ, Altman DG. Empirical evidence of bias. Dimensions of methodological quality associated with estimates of treatment effects in controlled trials. JAMA 1995;273:408-12.

5 Moher D, Pham B, Jones A, Cook DJ, Jadad AR, Moher M, et al. Does quality of reports of randomised trials affect estimates of intervention efficacy reported in meta-analyses? Lancet 1998;352:609-13.

6 Kjaergard LL, Villumsen J, Gluud C. Reported methodologic quality and discrepancies between large and small randomized trials in metaanalyses. Ann Intern Med 2001:135:982-9.

7 Begg C, Cho M, Eastwood S, Horton R, Moher D, Olkin I, et al. Improving the quality of reporting of randomized controlled trials. The CONSORT statement. JAMA 1996;276:637-9.

8 Egger M, Bartlett C, Jüni P. Are randomised controlled trials in the BMJ different? [letter]. BMJ 2001;323:1253-4.

9 Easterbrook PJ, Berlin JA, Gopalan R, Matthews DR. Publication bias in clinical research. Lancet 1991;337:867-72.

10 Dieppe P, Chard J, Tallon D, Egger M. Funding clinical research. Lancet 1999;353:1626.

11 Davidoff F, DeAngelis CD, Drazen JM, Hoey J, Højgaard L, Horton R, et al. Sponsorship, authorship, and accountability. Ann Intern Med 2001;135:463-6.

12 Moher D, Schulz K, Altman D. The CONSORT statement: revised recommendations for improving the quality of reports of parallel-group randomised trials. Lancet 2001:357:1191-4.

(Accepted 20 February 2002)

\title{
Effect of prenatal exposure to oestrogen on quality of semen: comparison of twins and singleton brothers
}

Lone Storgaard, Jens Peter Bonde, Erik Ernst, Claus Yding Andersen, Kirsten Ohm Kyvik, Jørn Olsen

Department of Occupational Medicine, Aarhus University Hospital, DK 8000 Aarhus,

Denmark

Lone Storgaard managing director Jens Peter Bonde professor

Laboratory for Reproduction, Institute of

Anatomy, University

of Aarhus, DK 8000

Aarhus

Erik Ernst

associate professor

Danish

Epidemiology

Science Centre,

University of

Aarhus

Jørn Olsen

professor

continued over

BMJ 2002;325:252-3

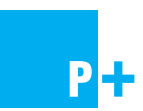

Figure A shows how the study groups were established and table $A$ gives characteristics of the participants.
The decline in sperm count and increase in disorders of the male reproductive tract may be due to high concentrations of prenatal exposure to oestrogens. ${ }^{1-2}$ As the concentration of free oestrogens in plasma is much greater in twin pregnancies from the first weeks of gestation, and greater for dizygotic twins than monozygotic twins, ${ }^{3-4}$ we studied sperm count in twins and singleton brothers to see if twin brothers have lower sperm counts and if the lowest values are for dizygotic twins.

\section{Participants, methods, and results}

From the population based Danish twin registry, we selected 250 monozygotic and 250 dizygotic pairs of twin brothers and from the Danish civil registration 500 pairs of singleton brothers. All the men were 20-45 years old and born in Denmark.

Of the 2000 men, $778(38.9 \%)$ agreed to participate (40\% of the singletons (396), 39\% of the dizygotic twins (197), and $37 \%$ of the monozygotic twins(185)).

Characteristics of semen and sex hormones. Values are medians (interquartile range) unless otherwise indicated

\begin{tabular}{|c|c|c|c|c|c|c|}
\hline \multirow[b]{2}{*}{ Characteristic } & \multirow[b]{2}{*}{ Singletons $(n=105)$} & \multirow[b]{2}{*}{$\begin{array}{l}\text { Monozygotic twins } \\
(\mathrm{n}=104)\end{array}$} & \multirow[b]{2}{*}{$\begin{array}{l}\text { Dizygotic twins } \\
(\mathrm{n}=107)\end{array}$} & \multicolumn{3}{|c|}{$P$ value * } \\
\hline & & & & $\begin{array}{l}\text { Singletons } v \\
\text { monozygotic } \\
\text { twins }\end{array}$ & $\begin{array}{c}\text { Singletons } v \\
\text { dizygotic twins }\end{array}$ & $\begin{array}{l}\text { Singletons } v \\
\text { all twins }\end{array}$ \\
\hline $\begin{array}{l}\text { Sperm concentration } \\
\text { (millions/ml) }\end{array}$ & $60.0(26.0-99.0)$ & $71.5(26.5-115.0)$ & $55.0(25.0-103.0)$ & 0.65 & 0.78 & 0.42 \\
\hline Sperm volume (ml) & $3.5(2.8-4.5)$ & $3.4(2.6-4.0)$ & $3.5(2.5-4.5)$ & 0.76 & 0.33 & 0.67 \\
\hline Sperm total count (millions) & $185(96-367)$ & $237(78-434)$ & $208(84-328)$ & 0.83 & 0.86 & 0.47 \\
\hline $\begin{array}{l}\text { No }(\%) \text { of men with sperm } \\
\text { concentration }<20 \text { million/ml } \\
\text { (\% within each group) }\end{array}$ & $17(16)$ & $15(14)$ & $18(16)$ & 0.72 & 0.90 & 0.90 \\
\hline $\begin{array}{l}\% \text { of sperm with normal } \\
\text { morphology }\end{array}$ & $15(10-21)$ & $12(6-17)$ & $12(7-18)$ & 0.03 & 0.70 & 0.16 \\
\hline \multicolumn{7}{|l|}{ Sex hormone concentrations: } \\
\hline Testosterone (nmol/l) & $22.8(17.2-26.4)$ & $19.8(15.9-23.4)$ & $20.7(16.7-24.1)$ & 0.16 & 0.99 & 0.34 \\
\hline $\begin{array}{l}\text { Follicle stimulating hormone } \\
\text { (IU/I) }\end{array}$ & $3.9(2.9-5.1)$ & $3.6(2.1-6.2)$ & $4.4(3.2-5.9)$ & 0.07 & 0.39 & 0.23 \\
\hline Luteinising hormone (IU/I) & $2.3(1.5-2.9)$ & $2.3(1.6-3.0)$ & $2.4(1.8-3.4)$ & 0.12 & 0.04 & 0.04 \\
\hline Inhibin B (pg/ml) & $195(155-255)$ & $155(120-243)$ & $165(131-210)$ & $0.004 \ddagger$ & $0.43 \ddagger$ & $0.07 \ddagger$ \\
\hline
\end{tabular}

*Adjusted for duration of sexual abstinence, urogenital disorders, alcohol, age, smoking, season, and birth weight.

†Morphology scored according to the World Health Organization's 1999 guidelines.

‡Also adjusted for sampling time. 
Because of our estimates of suitable sample size, we stopped enrolment when we had collected semen samples from 105 singleton brothers, 104 monozygotic twins, and 107 dizygotic twins.

The men produced semen by masturbation and we analysed it in less than 1.5 hours in a mobile laboratory at the participants' home $(\mathrm{n}=113)$ or at a stationary laboratory $(n=203)$. The sperm concentration was counted in an improved Neubauer haemacytometer (Marienfeld, Lauda-Königshofen); sperm morphology was classified according to 1999 World Health Organization criteria.

Sperm counts and sex hormone concentrations were positively skewed, and we transformed them to their cubic root to normalise their distributions. Morphology measurements were logit transformed. All potential confounders were included in the multiple linear regression.

The crude median sperm count was 19\% higher among monozygotic twins and 9\% lower among dizygotic twins than among singletons (table). The groups did not differ significantly with respect to any of the measures of semen quantity and quality. Inhibin B concentrations were significantly higher for singletons than for monozygotic twins.

We did not expect selection bias due to differential fertility to explain our findings: we found no difference between men who agreed to participate and those who did not in terms of the number of children they had $(1.8 \sim 1.9)$.

\section{Comment}

Higher prenatal concentrations of oestrogen are not related to reduced sperm counts in adulthood. In particular, we did not find lower sperm counts in twin brothers: both the concentration and potency of oestrogens during pregnancy with twins are greater than for most environmental oestrogens. ${ }^{5}$

The low inhibin B concentration in monozygotic twins is surprising and could reflect slower multiplication of Sertoli's cells in fetal life. If so, high sperm counts indicate a compensatory mechanism which should be present in both monozygotic and dizygotic twins. Inhibin B is a new marker of testicular function, and deeper insight about its importance for male reproduction is needed.

We thank Gorm Dancher, research technician Kirsten Lunding, and technicians at the laboratory at the Institute of Anatomy, Aarhus University.

Contributors: JO and JPB had the idea for the study. EE was the laboratory adviser. CYA analysed inhibin B. KOK withdrew twins from the Danish twin registry. LS designed the study. JO, $\mathrm{JPB}$, and LS collected and analysed the data. All of the authors wrote the paper.

Funding: Danish Research Council (Jnr 9802562), Danish Ministry of Health: Research Centre for Environmental Health Found (Jnr 383-4-1999), Danish Health Insurance Fund (Jnr 11/207-98 and 2000B514), and Danish Epidemiology Science Centre, University of Aarhus, Denmark.

Competing interests: None declared.

1 Sharpe RM, Skakkebaek NE. Are oestrogens involved in falling sperm counts and disorders of the male reproductive tract? Lance 1993;341:1392-5.

2 Gill WB, Schumacher GF, Bibbo M, Straus FH, Schoenberg HW. Association of diethylstilbestrol exposure in utero with cryptorchidism, testicular hypoplasia and semen abnormalities. J Urol 1979;122:36-9.

3 Johnson MR, Bolton VN, Riddle AF, Sharma V, Nicolaides K, Grudzinskas JG, et al. Interactions between the embryo and corpus luteum. Hum Reprod 1993;8:1496-501

4 Kappel B, Hansen K, Moller J, Faaborg-Andersen J. Human placental lactogen and dU-estrogen levels in normal twin pregnancies. Acta Genet Med Gemellol (Roma) 1985:34:59-65.

5 Daston GP, Gooch JW, Breslin WJ, Shuey DL, Nikiforov AI, Fico TA, et al. Environmental estrogens and reproductive health: a discussion of the human and environmental data. Reprod Toxicol 1997;11:465-81. (Accepted 22 January 2002)
Laboratory of
Reproductive Biology, University Hospital of Copenhagen, DK 2100 Copenhagen, Denmark

Claus Yding Andersen senior researcher

Danish Twin Registry, Institute of Community Health and Centre of

Health and Socia Policy, DK 5000 Odense, Denmark

Kirsten Ohm Kyvik associate professor

Correspondence to: L Storgaard lstor@aaa.dk

\section{A memorable patient "When can I go home?"}

It was a routine referral to the rheumatology clinic: a general practitioner had requested advice about the management of arthritic pain in a 78 year old woman. We met her at the Friday afternoon clinic, when she came with her daughter in law. Her joint pain had improved since she had seen her general practitioner. She had osteoarthritic changes in her hands and knees, as expected, but no features of inflammatory arthritis. She was remarkably thin and had recently lost a lot of weight. I wondered whether she had an underlying malignancy. She agreed to routine admission for further investigation. Her only concern was how long she would have to stay in, as she was looking after her husband, who had Parkinson's disease. The couple had been married for 50 years, and they lived on their own but under the close supervision of their children. They were planning to celebrate their 50th wedding anniversary with a holiday abroad.

Blood tests revealed a high erythrocyte sedimentation rate, anaemia, and raised alkaline phosphatase. We telephoned and explained that she needed to be admitted urgently. The same question was asked: "How long do I have to stay in?" and we said at least a week. She came in and was accommodated in a nice room on her own. The chest $x$ ray showed "nodules" in her lungs consistent with carcinoma. We told her children of this possibility. We told her that her $x$ ray showed possible old infection (she had had tuberculosis) but that she needed further investigation. We decided at this time not to mention anything to her about possible cancer.
By the fifth day of admission, she felt well in herself and had managed to put on some weight. She was desperate to go home as she was worried about her husband even though the results of computed tomography would not be available until the next day. We agreed to send her home, and she was dressed in 10 minutes and ready to go. She thanked all of us.

The next day, the tomogram of the chest confirmed an inoperable tumour with secondaries. She returned to the ward and calmly accepted the idea of having a tumour when we broke the news. "I never thought I had cancer," she said. Her only concern was for her husband.

Throughout our relationship with this woman, our priorities had been extensive investigation to discover the tumour, whereas hers were simply wondering how her husband would cope without her both immediately and in the future-whether or not she knew about the tumour.

Do we always realise what elderly people are trying to tell us when they ask to go home? Their priorities may be different from our perception of their medical needs.

Aml Abdala senior house officer in rheumatology

Dimitrios Kassimos locum consultant rheumatolosist, department of rheumatology, Dudley Group of Hospitals NHS Trust, Dudley

Dr Kassimos is on a study leave from the Ministry of Defence of Greece. 